\title{
A Summer Calculus Experience to Encourage Development of Community and Self-Efficacy Building of Civil Engineering Students
}

\section{Dr. Mary Katherine Watson, The Citadel}

Dr. Mary Katherine Watson is currently an Associate Professor of Civil and Environmental Engineering at The Citadel. Prior to joining the faculty at The Citadel, Dr. Watson earned her PhD in Civil and Environmental Engineering from The Georgia Institute of Technology. She also has BS and MS degrees in Biosystems Engineering from Clemson University. Dr. Watson's research interests are in the areas of engineering education and biological waste treatment.

\section{Dr. Simon Thomas Ghanat P.E., The Citadel}

Dr. Simon Ghanat is an Associate Professor of Civil and Environmental Engineering at The Citadel (Charleston, S.C.). He received his Ph.D., M.S., and B.S. degrees in Civil and Environmental Engineering from Arizona State University. His research interests are in Engineering Education and Geotechnical Earthquake Engineering. He previously taught at Bucknell University and Arizona State University.

\section{Dr. Timothy Aaron Wood, The Citadel}

Timothy A Wood is an Assistant Professor of Civil and Environmental Engineering at The Citadel. He acquired a Bachelor's in Engineering Physics Summa Cum Laude with Honors followed by Civil Engineering Master's and Doctoral degrees from Texas Tech University. His technical research focuses on the intersection of soil-structure interaction and structural/geotechnical data. He encourages students pushing them toward self-directed learning through reading, and inspiring enthusiasm for the fields of structural and geotechnical engineering. Dr. Wood aims to recover the benefits of classical-model, literature-based learning in civil engineering education.

\section{Dr. William J. Davis P.E., The Citadel}

William J. Davis is D. Graham Copeland Professor of Civil Engineering and Dept. Head of Civil, Environmental and Construction Engineering at The Citadel in Charleston, SC. His academic experience includes transportation infrastructure planning and design, infrastructure resilience, traffic operations, highway safety, and geographic information systems. His research interests include constructing spatial databases for better management of transportation infrastructure, improving transportation design, operation, safety and construction, understanding long-term effects of urban development patterns, and advancing active living within the built environment for improved public health. He teaches courses in interchange design, transportation engineering, highway design. engineering management, geographic information systems, and land surveying. He has served in numerous leadership positions in ITE, ASCE and TRB.

\section{Dr. Kevin C Bower P.E., The Citadel}

Dr. Kevin Bower is a Professor of Civil and Environmental Engineering and the Associate Provost for Academic Operations at The Citadel, Charleston, South Carolina. Dr. Bower's teaching research interests are in improving active learning environments and the development of classroom pedagogy to improve moral development in engineering students.

\section{Dr. Tara Hornor, The Citadel}

Dr. Tara Hornor currently serves an Associate Professor in the Zucker Family School of Education with a joint appointment to The Citadel's Department of Leadership Studies. She previously served as Associate Provost for Planning, Assessment, and Evaluation and Dean of Enrollment Management at The Citadel from 2008-2019, providing leadership for the institution's strategic planning, accreditation, assessment, institutional research, admissions, financial aid, and graduate college offices. Dr. Hornor holds a Ph.D. in Higher Education Administration from the University of Arizona and master's degrees in school counseling, instructional design, and human resource management. She is also a 2014 graduate of Harvard University's Institute for Management and Leadership in Education (MLE) and a 2009 graduate of Harvard University's Performance Assessment in Higher Education Institute. 


\section{Dr. Ronald W. Welch P.E., The Citadel}

Ron Welch (P.E.) received his B.S. degree in Engineering Mechanics from the United States Military Academy in 1982. He received his M.S. and Ph.D. degrees in Civil Engineering from the University of Illinois, Champaign-Urbana in 1990 and 1999, respectively. He became the Dean of Engineering at The Citadel on 1 July 2011. Prior to his current position, he was the Department Head of Civil Engineering at The University of Texas at Tyler from Jan 2007 to June 2011 as well as served in the Corps of Engineers for over 24 years including eleven years on the faculty at the United States Military Academy. 


\section{A Summer Calculus Experience to Encourage Development of Community and Self-Efficacy Building of Civil Engineering Students}

\section{Introduction}

The Citadel, a regional, residential military college, is currently engaged in a multi-year NSF S-STEM project to encourage persistence of academically-talented, low-income civil engineering students. Our Excellence in Civil Engineering Leadership (ExCEL) scholarship program builds on a prior program (of the same name) that included 34 scholarship recipients, of which $85 \%$ graduated with a STEM degree and $65 \%$ met the academic requirements to graduate as an ExCEL scholar [1]. The current ExCEL program seeks to retain several community-building and support services that were highly valued by our former students, including: (1) funding to attend the Citadel's College Success Institute prior to their freshmen year, (2) assignment to common barracks (or dormitories), (3) block scheduling into common courses, (4) access to an instructional strategist, and (5) opportunities to interact with professionals. However, of the students who left our first ExCEL program, 53\% cited calculus as one of the most important barriers to their persistence. Consequently, one key element of our new program is to develop and pilot approaches for improving student performance in early calculus courses. Specifically, during Summer 2019, six new ExCEL students participated in a summer experience focused on providing opportunities for community building and academic success related to calculus. This extended abstract provides details about the development, dissemination, and assessment of the Summer Calculus I Experience, with specific focus on how it aligns with broader ExCEL program goals.

\section{Theoretically-Informed Design of ExCEL Program}

Two of the major objectives of the ExCEL program are to: (1) Establish and foster a community of practice among S-STEM recipients, (2) Provide S-STEM students with opportunities to develop selfefficacy (particularly in early, barrier courses). Thus, literature related to communities of practice and self-efficacy were important to the design of programmatic elements.

\section{Community of Practice}

Based on positive feedback from our first set of ExCEL graduates, we are working to further develop communities of practice in our current ExCEL program. The description of communities of practice emerged from social learning theory to describe groups that interact regularly to engage in learning about a central focus [2]. Furthermore, a community of practice is a specialized learning community [3] in which "a group of people who share a concern, a set of problems, or a passion about a topic...deepen their knowledge and expertise in the area by interacting on an ongoing basis" [4]. Our premise is that through joint participation in the ExCEL program, our cohorts will form a community of practice around the "shared concern" of academic success for the purpose of pursing their "passion" of civil engineering.

Consequently, we are intentionally designing our support activities to address the three dimensions of communities of practice. Wenger [5] originally proposed and Kolikant, McKenna, \& Yalvac [6] summarized the key dimensions: (A) "What it is about": A joint enterprise as agreed upon by its members, (B) "How it functions": Mutual engagement that creates a social bond between members, and (C) "What capability it has produced": the shared repertoire of resources (e.g., vocabulary, artifacts) created by members. We have outlined several activities to encourage development of a community of practice among students (Table 1). The following are pertinent to the summer calculus experience:

1. The Citadel's College Success Institute (CSI): Our students participate in CSI before their freshman year. Through CSI, students are acquainted with campus life, familiarized with college resources, learn about the Corps of Cadets, begin building a support system, and earn academic credits. 
Commitment to CSI is the beginning of the students' joint enterprise as civil engineering students. Given the unusual combination of military and academic rigor of the first year, participation in CSI prior to the start of the academic year is expected to lead to early social cohesion among S-STEM students through mutual engagement in a more relaxed campus environment.

2. Co-Curricular Seminars: Regular engineering-based seminars are informed by students' needs/interests and used to guide them on their joint enterprise to become successful civil engineering students and professionals. Seminar events foster development of the shared repertoire of vocabulary and routines that are a necessary component of a community of practice.

\section{Provide Opportunities to Develop Academic Self-Efficacy}

Based on experiences with our prior scholarship program and student body more generally, we believe that students often exit civil engineering due to low math self-efficacy, rather than lack of ability. We expect that providing students with structured opportunities to develop self-efficacy, especially in barrier courses, will improve persistence.

Self-efficacy is one's own personal judgements about their abilities to achieve specific goals [7]. Indeed, self-efficacy positively impacts academic performance, with math and science self-efficacy being especially important for persistence of engineering students [8]. According to Bandura's Self Efficacy Framework [9], there are several types of information that can influence self-efficacy. The most impactful sources of self-efficacy are mastery experiences, which refer to one's direct experience of success or failure. Interaction with role models and seeing others' successful performances, or vicarious experiences, can also lead to self-efficacy building. Compliments or criticisms (social persuasions) can build or deteriorate one's self-efficacy. Finally, people's perceptions of their physiological arousal can impact their self-efficacy, with intense stress often indicating future failure. To encourage development of academic self-efficacy, we are employing several strategies (Table 1). The following are pertinent to the Summer I Calculus Experience:

1. New Sequencing of Barrier Math Requirements: S-STEM students complete their Calculus I course during the summer prior to their freshmen year. Calculus II is completed over two 16week semesters during their freshmen year. We anticipate that allowing students to complete their early math requirements over the summer will provide them with positive mastery experiences that will elevate their math efficacy.

2. Sessions with a Learning Strategist: During their freshmen and sophomore years, S-STEM students are connected to a trained learning strategist to help students understand the challenges of learning at the collegiate level, develop cognitive skills to successfully meet academic standards, and become active and independent learners. Learning strategists can help students manage the physiological arousal (e.g., stress) that is common during the first year, as well as be an important source of positive social persuasions.

3. Peer-Mentoring Program: As freshmen, students are assigned a mentor to help them navigate college. Interactions with mentors serve as vicarious experiences for underclassmen, although mentors may also provide positive social persuasions and advice for managing physiological arousal. 
Table 1. Alignment of student support services with S-STEM objectives (blue activities are prior, successful ExCEL initiatives, while green activities are newly-included for the current program).

\begin{tabular}{|l|l|l|l|}
\hline Objective \#1: Establish and Foster a Community of Practice \\
\hline \hline $\begin{array}{l}\text { Participation in Citadel } \\
\text { Success Institute* }\end{array}$ & $\begin{array}{l}\text { Block Scheduling } \\
\text { within Cohorts }\end{array}$ & $\begin{array}{l}\text { Assignment to } \\
\text { Common Barracks }\end{array}$ & $\begin{array}{l}\text { Co-Curricular } \\
\text { Seminars* }\end{array}$ \\
\hline \hline Objective \#2: Develop Academic Self-Efficacy & \\
\hline \hline $\begin{array}{l}\text { Summer Math \& Active } \\
\text { Learning Chemistry* }\end{array}$ & $\begin{array}{l}\text { Sessions with Learning } \\
\text { Strategist* }\end{array}$ & $\begin{array}{l}\text { Enhanced Faculty } \\
\text { Mentorship* }\end{array}$ & $\begin{array}{l}\text { Peer Mentoring } \\
\text { Program* }\end{array}$ \\
\hline \hline \multicolumn{2}{|l|}{ Objective \#3: Develop Professional Self-Efficacy } & $\begin{array}{l}\text { Participation in } \\
\text { Internship or Research }\end{array}$ \\
\hline \hline $\begin{array}{l}\text { Engagement with } \\
\text { Professionals through Site } \\
\text { Visits }\end{array}$ & $\begin{array}{l}\text { Early, Consistent } \\
\text { Professional Mentoring }\end{array}$ & $\begin{array}{l}\text { Professional } \\
\text { Conference } \\
\text { Attendance }\end{array}$ & \\
\hline
\end{tabular}

*Support service included in summer calculus experience.

\section{Summer Calculus I Experience}

The first ExCEL cohort arrived on campus during Summer 2019 (prior to their freshmen year) for the Summer Calculus I Experience. In total, seven students were invited to join the program after a thorough screening process which included interviews and successful completion of a standardized Math Placement Exam. All seven students were males, with two identifying as Hispanic and one as Black/African American. When comparing their Cost of Tuition to their Estimated Family Contribution, five students were designated as High Need and one was designated as Medium need by Financial Aid at The Citadel. Shortly after arriving for CSI, one student chose to change his major.

\section{Integration with Citadel Success Institute}

The Summer Calculus I Experience was integrated into the existing Citadel Success Institute (CSI), a program where students live on campus for three weeks to engage in military training, academic courses, and college success seminars. Our students began their Calculus I course during CSI, as well as participated in all other enrichment activities. After returning home for a week-long break, our students returned for a second three-week term to complete their Calculus I course, as well as participate in several supplementary community building activities. Of note, students were connected with a peer civil engineering leader who mentored students throughout the summer. The leader lived on campus with students, participated in team-building exercises, military training, and social activities.

\section{Course Structure}

Calculus I was taught with both face-to-face and online components over a six-week term. Embedded within CSI, the face-to-face component was held five days per week in 110 minute sessions and led by a math instructor. Topics covered during instruction included: limits, continuity, differentiability, and integrability. We worked closely with our Department of Mathematical Sciences to ensure that all learning objectives addressed during a full-term Calculus I course were included in our accelerated summer course. Typical sessions included lecture time with intermittent problem-solving sessions. The course syllabus is available by request.

Online instruction and support were also used to help students engage more deeply with course materials. Content was managed by a separate instructor who coordinated with the face-to-face instructor to ensure alignment of activities and learning outcomes. Weekly, students were required to post and respond to questions on the online discussion board, which required them to demonstrate conceptual mastery of topics (rather than procedural problem solving). In addition, students completed weekly journal 
submissions, which required critical reflection of course preparation, performance, and application to civil engineering. Twice per week the instructor was available for tutoring sessions via an online platform. Sample discussion board questions and journal prompts are provided in Table 2.

Table 2. Sample journal prompts and discussion board questions used to support critical reflection and conceptual mastery of calculus topics.

\begin{tabular}{l} 
Sample Journal Prompts \\
\hline $\begin{array}{l}\text { What was the last math class that you took? When did you take it? How did you do in the class? } \\
\text { What were some study habits that you used to help you prepare for tests/quizzes? Were these } \\
\text { effective? Do you plan to use those study skills in this course or try some new study habits? }\end{array}$ \\
\hline $\begin{array}{l}\text { How is the Gateway exam? What are some problems you are struggling with? What has helped you } \\
\text { be more successful with taking the Gateway exam? Have you noticed improvements in you ability to } \\
\text { take derivatives? Provide specific examples of problems you were struggling to complete but have } \\
\text { now successfully mastered. What mistakes were you making? }\end{array}$ \\
\hline $\begin{array}{l}\text { What study habits did you use to be successful this term? How will you use what you have learned to } \\
\text { help you be a successful student during the upcoming year? What are some goals you will set for } \\
\text { yourself for the upcoming semester? }\end{array}$ \\
\hline \multicolumn{1}{|c|}{ Sample Discussion Board Questions } \\
\hline $\begin{array}{l}\text { Sketch the graph of a continuous function that meets the following requirements: f(3) }=4 ; \mathrm{f}^{\prime}(3)>0 ; \mathrm{f}(- \\
\text { 2) }=-1 ; \mathrm{f}(-2)<0 . \text { Upload a picture of a graph with your response. Write a few sentences stating why } \\
\text { you drew your graph the way you did. }\end{array}$ \\
$\begin{array}{l}\text { Below are some functions and their proposed derivatives. In each problem, there is a mistake. Choose } \\
2 \text { of the problems (different from ones your classmates have already chosen) and find the mistake. } \\
\text { Rework the problem correctly and write a sentence or two stating what was done incorrectly in each } \\
\text { problem. Take a picture of your work and upload it when finished. Example function and proposed } \\
\text { derivative: } y=e^{3 x} ; y^{\prime}=3 x e^{3 x-1}\end{array}$ \\
\hline $\begin{array}{l}\text { Choose one application of a derivative and one application of an antiderivative and give specific } \\
\text { examples of how these applications will be useful in engineering. Read through your classmates' } \\
\text { responses and do not use the same specific engineering applications as another student. }\end{array}$ \\
\hline
\end{tabular}

\section{Parallel Engineering Seminar}

Approximately twice per week students attended a one-hour engineering seminar, hosted by a civil engineering faculty. The seminar was designed to provide students with tangible examples of how course material would connect with students' future classes and profession. Activities were related to early engineering fundamentals courses (e.g., statics, dynamics, and mechanics of materials), as well as applications of specific civil engineering subdisciplines (e.g., structural and transportation engineering) (Tables 3-4). The engineering faculty worked closely with course instructors to ensure that seminar activities aligned with recent course topics. Seminar deliverables and a comprehensive project accounted for $20 \%$ of the course grade. 
Table 3. Summary of activities completed in the parallel engineering applications seminar.

\begin{tabular}{|c|c|c|}
\hline Seminar Topic/Description & Math Skill/Topic & Application \\
\hline Spring stiffness experiment & Linear Models & Physics \\
\hline Car breaking experiment & Linear Models & Dynamics \\
\hline $\begin{array}{l}\text { Determining the angles and sides of trusses and frames } \\
\text { around campus experimentally and comparing them with } \\
\text { the theoretical values }\end{array}$ & $\begin{array}{l}\text { Law of Sines and } \\
\text { Cosines }\end{array}$ & Statics \\
\hline Determining position, velocity, acceleration & Differentiation & Dynamics \\
\hline $\begin{array}{l}\text { Determining shear, bending moment and deflection of } \\
\text { simply supported beam experiment (student standing at the } \\
\text { middle of beam) }\end{array}$ & Differentiation & $\begin{array}{l}\text { Structural } \\
\text { Engineering }\end{array}$ \\
\hline $\begin{array}{l}\text { Determining deflection and slope of centrally loaded simply } \\
\text { supported beam }\end{array}$ & Differentiation & $\begin{array}{l}\text { Structural } \\
\text { Engineering }\end{array}$ \\
\hline $\begin{array}{l}\text { Determining the highest elevation of vertical curve and } \\
\text { tangent slope }\end{array}$ & Differentiation & $\begin{array}{l}\text { Transportation } \\
\text { Engineering }\end{array}$ \\
\hline $\begin{array}{l}\text { Determining the modulus of elasticity (bar breaking } \\
\text { experiment) }\end{array}$ & Differentiation & $\begin{array}{l}\text { Mechanics of } \\
\text { Materials }\end{array}$ \\
\hline Determining the work done on stretching a spring & Differentiation & Dynamics \\
\hline Determining maximum normal and shear stress in a beam & Differentiation & $\begin{array}{l}\text { Mechanics of } \\
\text { Materials }\end{array}$ \\
\hline
\end{tabular}

Table 4. Summary of select activities from parallel engineering applications seminar.

Determining the angles and sides of trusses and frames around campus experimentally and comparing them with the theoretical values

During the first seminar meeting, students walked around campus of University " $X$ " and measured angles on trusses and other structures using protractors and tape measures (Figure 1). They broke into groups and each group had a person designated to measure, one designated to draw a picture of the triangle, and a person designated as data recorder. After taking several measurements of triangles, students calculated the values of angles and sides for each triangle using the laws of sines/cosines and or right triangles and compared results with the measured values of each angle for each triangle. Students then used peer instruction to explain their finding to the other groups.

\section{Structural Engineering Application}

Students investigated the bending moment, internal shear forces, and the deflection. Engineering faculty discussed the concepts related to shear and bending moment and deflections. The faculty asked one student to step on a five feet long board, which was supported at each end. He asked students to locate the points of zero shear force, zero bending moment, and zero deflection on the beam. Students modeled this problem as a simply supported centrally load beam shown in the figure below and student's weight was used as the load exerted in the middle of beam. Students also calculated the shear force functions by differentiating the bending moment functions. Students employed calculus to determine the locations of maximum shear force, maximum bending moment and maximum deflection on the beam. They plotted the graph of shearing force and bending moment functions vs. length of the beam. Furthermore, students applied calculus to determine an equation for the deflection function, and the locations of the maximum deflection and zero slope on the beam.

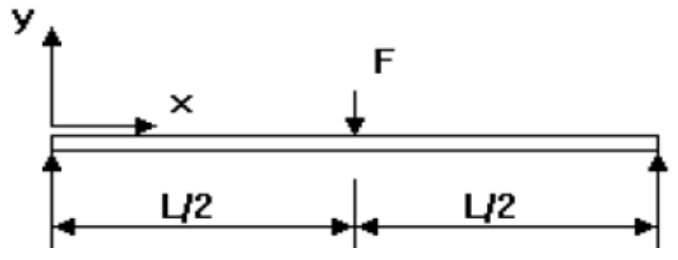




\section{Transportation Engineering Application}

On one of the later meetings, engineering faculty discussed the highway geometry concepts. As a seminar activity, he asked students to use their calculus knowledge to determine the elevation of the highest point on the vertical curve shown in Figure 3 (students were given the elevation of the point of vertical curve (PVC) and the equation of vertical curve $\left.\mathrm{Y}=\mathrm{Y}_{\mathrm{PVC}}+\mathrm{g}_{1} \mathrm{X}+\mathrm{ax}^{2} \quad \mathrm{a}=\left(\mathrm{g}_{2}-\mathrm{g}_{1}\right) / 2 \mathrm{~L}\right)$. Calculus was further used to determine the tangent slope at various stations in Figure 3.

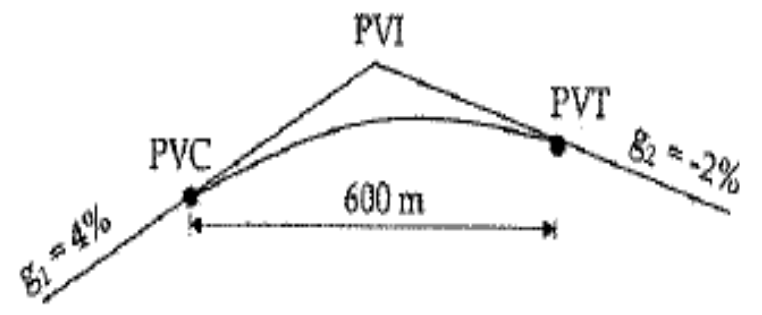

\section{Academic Support}

In addition to support from math and engineering faculty, students also worked closely with a supplemental instructor and an instructional strategist. The supplemental instruction leader was a graduate student in math education who attended all classes and led approximately three one-hour sessions per week to allow students to practice problems, ask homework questions, and prepare for exams. Given the accelerated pace of the course, supplemental instruction sessions were essential to ensure that students had ample time to engage with new material. The instructional strategist was a staff member within Academic Affairs with extensive experience coaching undergraduates. The strategist met with scholarship students as a group weekly to discuss time management, study habits, and specific challenges related to the course. In addition, the strategist met individually with students once per week to discuss their performance and aid in development of study plans. Meetings with the strategist were important to facilitate (early) transition to college-life and management of the accelerated course format.

\section{Assessment of Summer Calculus Experience}

\section{Course Performance}

While the accelerated pace proved to be difficult for most students, performance in the Calculus I course was high overall. All students earned the required " $\mathrm{C}$ " or higher required to enroll in Calculus II. In contrast, 35\% of students' peers who enrolled in Calculus I during Fall 2019 did not earn a " $\mathrm{C}$ " or higher. In addition, all scholarship students successfully passed the Gateway Exam, which is a computer-based exam to test computation skills. In contrast, $26 \%$ of the scholarship students' peers who completed traditional Calculus I courses did not pass the Gateway Exam. Notably, even ExCEL students with lower math placement exam scores and/or scholarship matrix scores passed the Gateway Exam and met requirements to proceed to Calculus II.

\section{Community-Building}

At the beginning of their first fall semester, students participated in a focus group to reflect on their summer experiences. The facilitator asked students' to "describe [their] ExCEL group." Uniformly, students used the words "close" and "family" to describe the relationships that formed over the summer. Ryan even described development of a "brotherhood." Indeed, students recounted the closeness that they had developed with each other, describing study sessions and competitive racquetball in their free time. 
In addition, students agreed that their community included their peer leader and professors, in addition to the group of six scholarship students. For example, Glenn described the "trust" that the group had developed with their engineering seminar faculty. Luke described the advantages of already knowing "four or five teachers before the school year [started]." Glenn also summarized that "if you're struggling, someone will notice." Results from the focus group confirmed that the group had formed lasting bonds through their summer calculus experience that were continuing to help them during the regular academic year [mutual engagement]. Also, the impact of the parallel engineering seminar clearly helped in bonding the students together as engineers [joint enterprise], while also helping them to connect new math concepts with engineering practice [shared repertoire].

At the end of their first spring semester, students participated in a second focus group to reflect on their summer and its impact on their first-year experience. The facilitator again asked students' to "describe [their] ExCEL group." Students continued to use descriptors like "life-long friends" and "family away from home" to describe the relationships that formed over the summer and continued to strengthen over the year. Luke even described the group as his main point of outreach, stating "I'm going to come to this group first if I have a life problem, not just a math problem." In addition, students included their learning strategist and professors in their description of community, including using terms like "second mother" and "support team." Glenn also stated as a result of their summer experience, "we already knew these teachers and their teaching styles. So that really [helped us] get over the first two-week leap of having to learn your teacher because we already knew them from the summer."

\section{Self-Efficacy Building}

Math self-efficacy was captured using three different methods. First, students completed a previouslydeveloped, Likert-type math self-efficacy questionnaire [10] both before and after their summer calculus course (Table 5). Overall, three students (Blake, Glenn, and Jason) showed higher self-efficacy after the course, while two students (Ryan and Luke) showed lower self-efficacy after the course. One student (Cody) showed almost no change in self-efficacy. Patterns in this data are still being explored; however, we observe that students who completed AP Calculus prior to the summer course clearly demonstrated improved self-efficacy. In contrast, only one student who completed Precalculus prior to the summer course demonstrated improved self-efficacy. Furthermore, the student (Ryan) who entered the course with the lowest Math Placement Exam Score showed the greatest drop in self-efficacy.

Second, at the end of the questionnaire, students were asked to provide written reflections on how the summer experience impacted their confidence in their math skills. Overall, the feedback indicated general improvements in math self-efficacy and aligned somewhat with the quantitative data. For example, Blake (highest initial MPE score) described great improvements in self-efficacy: "The summer experience has only affected my confidence in my math skills positively. I feel like I have a better understand[ing] of calculus now [than] before and [I] can help others as well." Glenn (lowest initial MPE score; greatest drop in SE score) described less significant impacts: "I feel like it boosted my confidence a little more."

Finally, insights about development of students' self-efficacy were gleamed from two focus groups. The facilitator asked students: "How does it feel to have successfully completed Calculus before the start of school?" Immediately, the students smiled as they all agreed that it felt "really good" (mastery experience). Blake recounted that he was able to develop "better study habits" that were continuing to serve him during the academic year. Students shared anecdotes about their peers struggling through Calculus I while transitioning to college and military life without the academic and community support that they received in the summer. Luke described that he felt calmer and less stressed during his first semester because of his accomplishments during the summer (positive physiological arousal). 
In the second focus group conducted at the end of their first spring semester, students continued to communicate the value of taking Calculus in the summer, making statements like it "was time well spent" and "looking back I wouldn't spend the summer any other way." The students also highlighted the value of supplemental instruction and tutoring services during the summer. For example, Glenn described the support services as "offering another way of teaching" and as "a fourth set of instruction," on the same topic. When describing supplemental instruction, Glenn commented it was "really helpful having her in class because she understood and could feel what we weren't understanding in class and then she was able to go over that afterward." In addition, Blake stated to be successful "you had to do all the extra resources- tutoring, SI, and that those all came together to help everyone out" and that "during the school year we just transitioned that thought process to every other class or at least the ones that were difficult like Calculus and that became the standard of how much time you needed to spend on classes." Overall, it was clear from the focus groups that students were very proud about their summer accomplishments and felt empowered to begin the semester. Perhaps the results of the focus group supported greater (and more uniform) improvements in students' academic self-efficacy because they were able to compare their success to the struggles of their peers who did not participate in the summer experience.

Table 5. Comparison of students' self-efficacy scores with their financial need, math preparedness, and Calculus I performance.

\begin{tabular}{c|c|ccc|cc|ccc} 
Alias & $\begin{array}{c}\text { Financial } \\
\text { Need }\end{array}$ & Matrix $^{2}$ & MPE & $\begin{array}{c}\text { Highest } \\
\text { HS Math }\end{array}$ & $\begin{array}{c}\text { Calculus } \\
\text { I Grade }\end{array}$ & $\begin{array}{c}\text { Gateway } \\
\text { Exam }\end{array}$ & $\begin{array}{c}\text { Math } \\
\text { SE } \\
(\text { Pre })^{2}\end{array}$ & $\begin{array}{c}\text { Math } \\
\text { SE } \\
(\text { Post })^{2}\end{array}$ & $\begin{array}{c}\% \\
\text { Difference }\end{array}$ \\
\hline Blake & High & 26 & 28 & AP Calc & A & Pass & 115 & 126 & 9.6 \\
Glenn & Medium & 27 & 25 & AP Calc & A & Pass & 108 & 116 & 7.4 \\
Cody & High & 18 & 21 & Precalculus & B & Pass & 104 & 103 & -1.0 \\
Ryan & High & 16 & 16 & Precalculus & C & Pass & 92 & 77 & -16.3 \\
Luke & High & 32 & 24 & Calculus & A & Pass & 115 & 108 & -6.1 \\
Jason & High & 17 & 22 & Precalculus & B & Pass & 112 & 120 & 7.1
\end{tabular}

${ }^{1}$ The Matrix score is computed by The Citadel's Financial Aid to summarize the academic merit of prospective students.

${ }^{2}$ Responses on the Math Self-Efficacy Questionnaire (MSEQ) were summed for each student. Reverse coding was used for items that indicated low/negative self-efficacy prior to summation.

\section{Summary and Future Work}

The ExCEL scholarship program aims to recruit and retain high-performing, low income scholarship students by providing academic and professional support activities that encourage self-efficacy building through development of a community structure. To date, the first six scholarship students have completed a new Summer Calculus I Experience in which they completed an accelerated Calculus I course prior to their first academic year. The course was embedded within an existing college success program that was expanded to two three-week terms to accommodate the rigors of an advanced math course. Participation in the summer program gave students access to two math instructors, a civil engineering professor, a supplemental instructor, an instructional strategist, and a peer mentor. Quantitative and qualitative assessment of the summer program supports that indeed the course served as a mastery experience that boosted students' self-efficacy, although the degree of improvement may vary by student. Future work will include tracking student performance in their two-semester Calculus II course, as well as future engineering courses. The summer program will also be adapted for future scholarship cohorts.

\section{Acknowledgements}

This material is based upon work supported by the National Science Foundation under Grant No. 1741611. Any opinions, findings, and conclusions or recommendations expressed in this material are those of the authors and do not necessarily reflect the views of the National Science Foundation. 


\section{References}

1. Watson, M.K., K.C. Bower, and W.J. Davis. Advancing diversity initiatives in the civil engineering profession: Impacts of an NSF S-STEM grant at a regional undergraduate teaching institution, in American Society for Engineering Education Annual Conference and Exposition. 2017. Columbus, $\mathrm{OH}$.

2. Wenger, E., Communities of practice and social learning systems: The career of a concept, in Social Learning Systems and Communities of Practice. 2010, Springer. p. 179-198.

3. Li, L.C., et al., Evolution of Wenger's concept of community of practice. Implementation Science, 2009. 4(1): p. 11.

4. Wenger, E., R.A. McDermott, and W. Snyder, Cultivating communities of practice: A guide to managing knowledge. 2002: Harvard Business Press.

5. Wenger, E., Communities of practice: Learning, meaning, and identity. 1998: Cambridge university press.

6. Kolikant, Y.B.D., A. McKenna, and B. Yalvac, The emergence of a community of practice in engineering education. New Directions for Teaching and Learning, 2006 (108): p. 7-16.

7. Yildirim, T., M. Besterfield-Sacre, and L. Shuman, Scale development for engineering modeling self efficacy, in American Society for Engineering Education Annual Conference \& Exposition. 2010: Louisville, KY.

8. Usher, E.L., et al., Sources of self-efficacy in undergraduate engineering, in American Society for Engineering Education Annual Conference \& Exposition. 2015: Seattle, WA.

9. Bandura, A., Self-efficacy: Toward a unifying theory of behavioral change. Psychological review, 1977. 84(2): p. 191.

10. May, D.K., Mathematics self-efficacy and anxiety questionnaire. Unpublished doctoral dissertation, University of Georgia, Athens, USA, 2009. 